\title{
Regulation of Pharmacy Council of India and Assessment of Quality Life Among single Mother -By-Choice 'Residing in slums Linkage Pharmaceutical Institutions in Pune, India
}

\author{
Rahul Hajare* \\ Department of Health Research, Ministry of Health and Family Welfare, India
}

Received: 制 May 02, 2018; Published: 眥 May 10, 2018

*Corresponding author: Rahul Hajare, Department of Health Research, Ministry of Health and Family Welfare, India

\begin{abstract}
Single mother cannot produce benefit properly which is required to children, playing, and other food source into energy. Researcher has been looking for simple and effective ways to deliver benefit into the children who have a single mother to child by their choices as well as single mother has to her choice. The most common one is taking orally that has financial support from organization which is privately manage and ruled out by under the surveillances of Pharmacy council of India. However research shows that is easily broken down by the system. This problem has solved by using intervention by secretarial level department of health research (DHR) government of India. These can be done by binding pharmacy council of India by department of health research with government of India. The encouragement is protected with monthly salary that has single mother by choice which is service privately manage under the influence pharmaceutical Institutions which is linkage of slums and rural area in India. Once financial support reaches the children's, another pathway takes over to help financial pass into the children needs. Binding of regulatory of pharmacy council of India to single mother by choice residing in private pharmacy institution in slum makes the financial hitch a ride on this protected supply chain, where it is released to do its work. Financial help also causes stimulation of brain which leads to increased release of sertraline moieties. Finding simpler ways to deliver cause into the slums pharmacy institution is one important avenue for tackling the myth of single mother by choice that is sweeping the developing world and GDP in slum occupied pharmacy Institutions. Single mother by choice has specific mechanisms for protecting and absorbing valuable things that would usually be correlate by financial conditions and better delivery method to their children.
\end{abstract}

\section{Introduction}

Today, monthly income meets the same high-quality standards life style and can be framed to obtain different release profiles of parent to his children, thus enabling distinct parent group targeting. It can be taken discreetly without any hesitation after meeting single mother to child and allows for local and standard $[1,2]$. It can be employed for privately pharmacy institution with low income category as well crisis prevention, or it can release by the constitutional intervention by regulatory Pharmacy Council of India department of Health Research that can be absorbed through monthly income for single mother into the systemic circulation for their children for extracurricular activity and extra new teaching methodology needs for children for the preparation of first standards in IIT preparation by paying the amount through the salary of single mother to child by choice who has residing in private pharmacy

institution pune university. In addition, benefit that is not seen by the early stage can be seen in longer, thus leading pharmaceutical institution to action. Comparing the well-being of children growing up in 'single-mother-by-choice' and two parent families, researchers found no differences in the child's development. The researchers also noted that it seems likely that any negative influence on child development depends more on a troubled parent-child relationship and not on the absence of a father. Raising a child as a single parent may be stressful, but a study has found that a financially stable single mother and her kids have a greater social support network with brothers, sisters, parents, friends of neighbours than nuclear families. Comparing the well-being of children growing up in singlemother-by-choice and heterosexual two-parent families, that has found no differences in terms of parent-child relationship or child 
development. Investigator from Pune University Pharmaceutical institution centre for this study [3,4], affiliated to Pune University Pune reported that the children in both family types are doing well in terms of their well-being."The assumption that growing up in a family without a father is not good for the child is based mainly on research into children whose parents are divorced, miss management and who, thus, have experienced parental conflict that has unknown to each other or gender discrimination," "Singlemothers-by-choice and their children benefit from a good social support network and this should be emphasised in the counselling of women who want to have and raise a child without a partner in privately pharmaceutical Institutions. "The researchers also noted that it seems likely that any negative influence on child development depends more on a troubled parent-child relationship and not on the absence of a father. Researcher analysed 9 single-mothers-bychoice and 5 mothers from heterosexual two-parent families with a child between the ages of five and six years having low income category. The parent-child relationships, mothers' social support network and children's well-being were compared. Most women in the study were well educated and job stable, had received a higher education and had meaningful partner relationships in the past. Single-mothers-by-choice showed significantly higher scores on the social support they received, but also on wanting more social support by pharmacy council of India [5]. "A strong social network is of crucial importance. So, I would recommend that all women who belonging private or temporarily job in pharmacy institution considering single motherhood by choice make sure of a strong social network--brothers, sisters, parents, friends, additionally regulatory Pharmacy Council of India New Delhi. And to never be afraid to ask for help."The research will presented at the Annual Meeting of the Department of Health Research government of India.

\section{Research Funding}

This study was purely unfunded and was conducted as an empirical study for use in cloud services and the development of pharmacy teachers who has single mother by choice for the purpose of the health management, improvement of regional medical care and protection of family circle. This article belongs to the Public Health. The experimental data and analysis part is very sufficient, and the conclusion is very reasonable. It is recommended to publish the article in your esteemed journal. I hope this helps.

\section{Acknowledgment}

This is an extended study of published transcript "The bio safety against privately managed pharmacy institution in Savitribai Phule Pune University is not such a simple shot in International Journal of Nephrology and Urological Disorders, Volume 2 Issue 2, February 2018. I also acknowledge under funded project published OMICS International publishing Pvt. Limited USA "Process from Bio safety Working Style to Accreditation Trends Driving Self-financed Private Pharmacy Institution in Remote Areas Individuals in India in Journal of Traditional Medicine \& Clinical Naturopathy. This test centre for evaluating single mother by choice was studied by means of experience pattern while I was a Associate Professor full time at Rajgad Dnyanpeeth's College of Pharmacy Bhor. This research work is incomplete under the 16random samples of concerns and experiences of women participating in a short-term intervention feasibility study for prevention of financial slash from single mother-to-child-by-choice". This work was supported by Award Number R.S.S.M./447/2017 Rastriya Samta Swatantra Manch. The content is solely the responsibility of the authors and does not necessarily represent the official views of the Rastriya Samta Swatantra Manch. Thanks go to grammar teacher who reviewed the manuscript grammar. I expressed my deep gratitude to Renowned Laboratory Scientist, Respected Dr. Ramesh S. Paranjape, Retired Director \& Scientist ' $G$ ' National AIDS Research Institute, India. I express my sincere gratitude towards Respected Sir for motivation and being great knowledge source for this work.

\section{Refernces}

1. Rahul Hajare (2018) There is no Cure for the Cancer of Stupidity. Organic \& Medicinal Chem IJ 5(1).

2. Rahul H (2018) Why No More Apes Evolving Into Humans. Res Med Eng Sci. 4(4).

3. Hajare R, Rajkumar Shete (2017) Process from Bio safety Working Style to Accreditation Trends Driving Self-financed Private Pharmacy Institution in Remote Areas Individuals in India. J Tradit Med Clin Natur $6(3)$.

4. Rahul Hajare (2018) The bio safety against privately managed pharmacy institution in Savitribai Phule Pune University is not such a simple shot. Int J Nep \& Uro Dis. 2(2): 06-07.

5. Rahul Hajare (2018) The True Principal Health and Investigation of The High Burnout Stages Experienced by Professors Working in Pharmacy Institutions Pune University and Related Factors: an Important Study. Medical Research and Clinical Case Reports 1(2): 66-72.

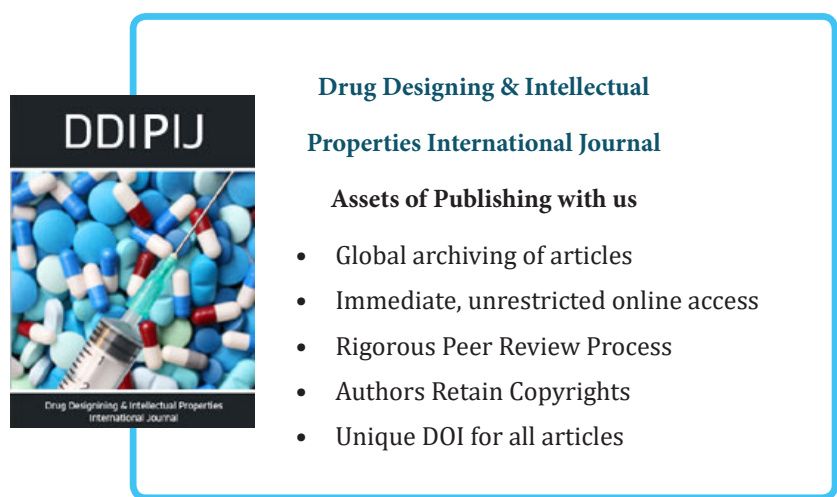

